\title{
Design of super-twisting algorithm control and observer for three-phase inverter in standalone operation
}

\author{
Dinh Hieu Phan ${ }^{1}$, Minh Tuan Dao ${ }^{2}$, Van Truong Nguyen ${ }^{1}$, Huy Anh Bui ${ }^{1}$, Ngoc Duy Le ${ }^{1}$, \\ Thanh Lam Bui ${ }^{1}$ \\ ${ }^{1}$ Department of Mechatronics Engineering, Faculty of Mechanic Engineering, Hanoi University of Industry, Hanoi, Vietnam \\ ${ }^{2}$ Department of Automation Engineering, Faculty of Electrical and Electronic Engineering, Hung Yen University of Technology and \\ Education, Hai Duong, Vietnam
}

\begin{abstract}
Article Info
Article history:

Received May 5, 2021

Revised Jan 29, 2022

Accepted Feb 5, 2022

Keywords:

Distributed generation systems inner-loop current controller Load voltage

Outer-loop voltage controller

ABSTRACT

This paper develops a new control algorithm of a distributed generation system in the standalone operation. Behavior of three-phase voltage source inverter is investigated and the guidelines for tuning the control parameters are presented. Based on super-twisting algorithm, the proposed controller guarantees the load voltage performance under different types of loads. The proposed controller is established for an inner-loop current controller and an outer-loop voltage controller in a dual control scheme. The proposed scheme is very simple, thus tuning control parameters is easy and the computational burden of the controllers is low. In order to validate the load current of the proposed system feasibility, a reduced-order observer is adopted. The simulation results indicate a more reliable and efficient performance compared to the standard sliding control and the adaptive control.
\end{abstract} super-twisting algorithm

Standalone operation

Total harmonic distortion

Corresponding Author:

Dinh Hieu Phan

Department of Mechatronics Engineering, Hanoi University of Industry

No. 298, Cau Dien Street, Bac Tu Liem District, Hanoi, Viet Nam

Email: phandinhhieu@haui.edu.vn
This is an open access article under the CC BY-SA license.

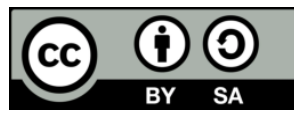

\section{INTRODUCTION}

Last century, there has been a rapid increase in the number of distributed generation systems (DGSs) because of their merits compared to the conventional central generation systems, such as decreasing systems and fuel cost, complying with stricter environmental regulations, and technological advances in small generators, power electronics, and energy storage devices [1]-[6]. The DGSs could be implemented in two different modes that are in stand-alone application (Islanded mode) [7] or grid-connected applications [8]. Especially, the stand-alone mode is applied as an optimal option in some cases, such as: expensive connection, and impractical location rural areas. During the stand-alone applications process, the DGSs implement in independent mode or in a parallel mode by connecting the DG units together. The most remarkable advantage of the parallel mode is good load sharing (harmonic power sharing, reactive power sharing, and real power sharing) by regulating real power and reactive power independently [9]. On the other hand, the independent mode has to maintain good performance (small steady-state error, low harmonic distortion, fast transient response) of the load voltage among complicated scenarios. In this article, the authors concentrate more on each DG behaviors during the independent operation in the Islanded mode.

Recently, several studies have been investigated on designing voltage controllers for three-phase voltage inverters in order to improve the load voltage performance. First, the conventional proportion-integral (PI) technique was presented for a single voltage control loop in [10]. Zhang et al. [11] proposed dual-loop scheme (the PI inner-loop current and the PI outer-loop voltage controllers). Even they maintain a good quality 
control during balanced loads operation, they were not appropriate for nonlinear loads. To deal with this problem, a harmonic power flow technique tailored for planning applications is designed in [12]. It resulted in a better distribution of dispatchable DGs, hence the high harmonic phenomena are reduced. During recent years, various advanced control methods have been developed for output voltage controllers. He et al. [13], an adaptive lyapunov-based control strategy for a single-phase uninterruptible power supply (UPS) inverter was proposed. Although this controller showed a good performance in the case of the nonlinear loads, it still consumes more time to validate and evaluate the output response of the micro-grid system.

A discrete-time repetitive controller is designed to maintain the performance of the UPS inverters load voltage [14]-[16]. Nevertheless, this method suffers from a series of pitfalls such as reduced conversion efficiency of the inverter or distorted output voltage in the UPS. Lucena et al. [17], a single-phase $\mathrm{AC} / \mathrm{DC} / \mathrm{AC}$ five-leg multilevel converters are proposed to ensure the output voltage quality in case of the unbalanced loads and the nonlinear loads. However, these controllers are too complicated to implement. The (proportional-derivative) PD voltage controller is equipped for DC/DC boost converters via current sensorless approach [18], but this approach could only process in the areas which install the active damping. Besides, one serious weakness of this method is the ability to stabilize the error dynamic. In order to deal with these complex issues, the sliding- mode control (SMC) has been proposed for UPS inverters [19], [21]. Komurgucil [19], precented the UPS inverters are designed by using the rotating-sliding-line-based slidingmode controller. Despite of smaller total harmonic distortion in the load voltage, the designed controller is only for the single-phase inverter. The SMC strategy is approached for doubly fed induction generator using extended active power [20]. Unfortunately, this method neglects to supervise the variable switch frequency of the converter effectively. Therefore, it causes the high chattering problem. The SMC strategy is also proposed to control the four-leg inverter [21]. This control strategy proves the robustness of the SMC system. However, total harmonic distortion (THD) of the load voltage is relatively high in the case of the nonlinear loads. The disadvantage of classical SMC above is characterized by a discontinuous control action which causes the chattering problem increasement. To overcome this problem, a super-twist sliding-mode control (STSMC) is proposed in many literature sources [22]-[28]. The advantage of this technique is characterized by continuous time of the control action. Thus, the chattering phenomenon is eliminated significantly.

In this paper, the STSMC strategy is involved in the dual-scheme with a STSMC inner-loop current controller and a STSMC outer-loop voltage controller under various load types. The method for tuning parameters of the proposed controller is designed. The most remarkable point to emerge from the STSMC controller is the continuous control actions which reduce the load voltage chattering. Hence, the quality of the load voltages is significantly improved. The STSMC controller is sufficiently simple, thus tuning controller parameters is easy and the computational burden of the controller is low. Moreover, a reduced-order observer of the load current is established to reduce the number of current sensors. As a result, the reliability and the cost-effectiveness of the designed system are enhanced. Finally, the simulation results show the good performance of the load voltages under various load types when compared to the standard sliding controller and adaptive controller.

The rest of this novel is divided as follows: The next section indicates a DGS description and mathematical model of a three-phase inverter. The STSMC controller and reduce-order observer designs are described in section 3. The simulation results are reported in section 4 . The final section illustrates the brief conclusion.

\section{STANDALONE DGS DESCRIPTION AND MATHEMATICAL MODEL}

A brief overview of the DGS based on renewable energy sources is depicted in Figure 1. There are three main parts in standalone DGS: Input powers, local loads, and the power conversion unit. To begin with, the input powers consist of different kinds of renewable energy sources, such as wind, fuel, and solar energy. Secondly, the power conversion unit is established by coupling the input converter (AC/DC converter or DC/DC boost converter), a three-phase inverter with an LC output filter. Finally, the power converter transmits the output voltage and the electric power to the local loads. The quality and reliability of them are regulated by the controllers. In this paper, the input powers and the input converter are replaced by a stiff DC voltage source.

The structure diagram of a three phase DC/AC converter applying the LC filter is presented in Figure 2. The mathematical model of the designed converter can be described as (1).

$$
\frac{d V_{2}}{d t}=\frac{1}{C_{1}} I_{1}-\frac{1}{C_{1}} I_{2} ; \frac{d I_{1}}{d t}=\frac{1}{L_{1}} V_{1}-\frac{1}{L_{1}} V_{2}
$$


Where $V_{1}$ is defined as a vector output voltage $V_{1}=\left[v_{1 a}, v_{1 b}, v_{1 c}\right]^{T}, I_{1}$ is defined as a vector current $I_{1}=\left[i_{1 a}, i_{1 b}, i_{1 c}\right]^{T}, V_{2}$ denotes a vector load voltage $V_{2}=\left[v_{2 a}, v_{2 b}, v_{2 c}\right]^{T}, I_{2}$ denotes a vector load current $I_{2}=\left[i_{2 a}, i_{2 b}, i_{2 c}\right]^{T}, L_{1}, C_{1}$ denotes the filter inductance and filter capacitor, respectively. The (1) which places in the stationary frame convert into the following equations in the synchronously rotating $d-q$ frame:

$$
\begin{aligned}
& \frac{d V_{1 d}}{d t}=w V_{1 q}-\frac{1}{C_{1}} I_{2 d}+\frac{1}{C_{1}} I_{1 d} ; \frac{d V_{2 q}}{d t}=-w V_{2 d}-\frac{1}{C_{1}} I_{2 q}+\frac{1}{C_{1}} I_{1 q} \\
& \frac{d I_{1 d}}{d t}=-\frac{1}{L_{1}} V_{2 d}+w I_{1 q}+\frac{1}{L_{1}} V_{1 d} ; \frac{d I_{1 q}}{d t}=-\frac{1}{L_{1}} V_{2 q}-w I_{1 d}+\frac{1}{L_{1}} V_{1 q}
\end{aligned}
$$

where as $w$ is defined as the frequency of the angular, $V_{2 d}, V_{2 q}$ denotes the load voltage of $d-q$ frame, and $I_{2 d}, I_{2 q}$ denotes the load currents of $d-q$ frame, respectively. Let us introduce the state variables $I_{1 d}=x_{1}, I_{1 q}=x_{2} ; V_{2 d}=x_{3} ; V_{2 q}=x_{4}$. In (2) could be rewritten as:

$$
\begin{aligned}
& \frac{d x_{1}}{d t}=-\frac{1}{L_{1}} x_{3}+w x_{2}+\frac{1}{L_{1}} V_{1 d} ; \frac{d x_{2}}{d t}=-\frac{1}{L_{1}} x_{4}-w x_{1}+\frac{1}{L_{1}} V_{1 q} \\
& \frac{d x_{3}}{d t}=w x_{4}+\frac{1}{C_{1}} x_{1}-\frac{1}{C_{1}} \hat{I}_{2 d} ; \frac{d x_{4}}{d t}=-w x_{3}+\frac{1}{C_{1}} x_{2}-\frac{1}{C_{1}} \hat{I}_{2 q}
\end{aligned}
$$

where $\hat{I}_{2 d} ; \hat{I}_{2 q}$ denote the estimation of the load currents $I_{2 d}, I_{2 q}$, respectively.

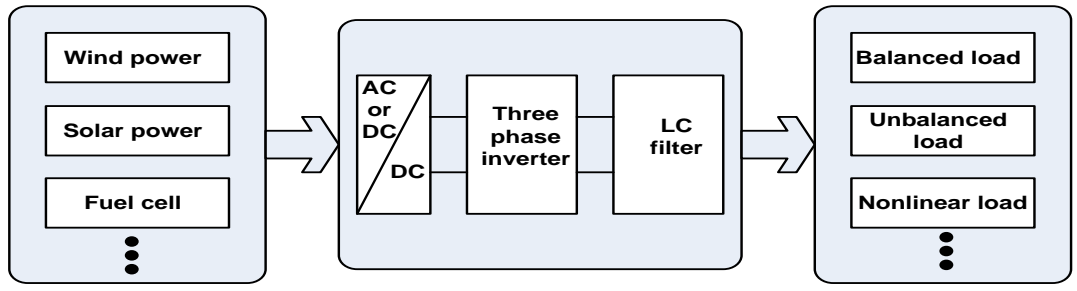

Figure 1. Block diagram of a standalone DGS

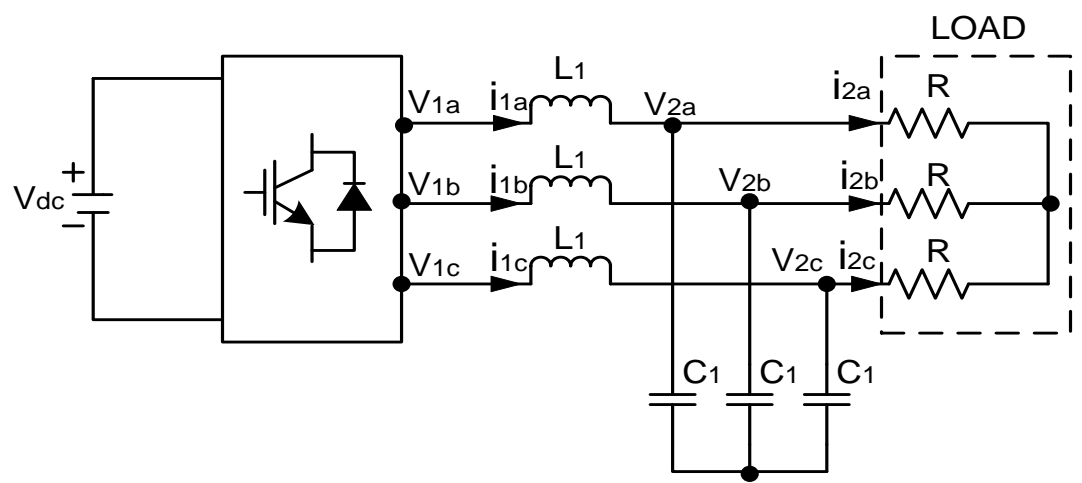

Figure 2. Structure diagram of the three-phase converter of standalone distributed generation systems

\section{STSMC TECHNIQUE AND REDUCE-ORDER OBSERVER DESIGN}

The proposed controller is designed based on the STSMC technique. To be more specific, a dual structure is established by combining the inner loop of current controller and the outer loop of voltage controller. Both of them are involved the STSMC technique to calibrate the load voltage. In addition, an observer of the load current is established for calculating the voltage loop controller. The proposed STSMC and the observer in stand-alone mode is depicted in Figure 3. 


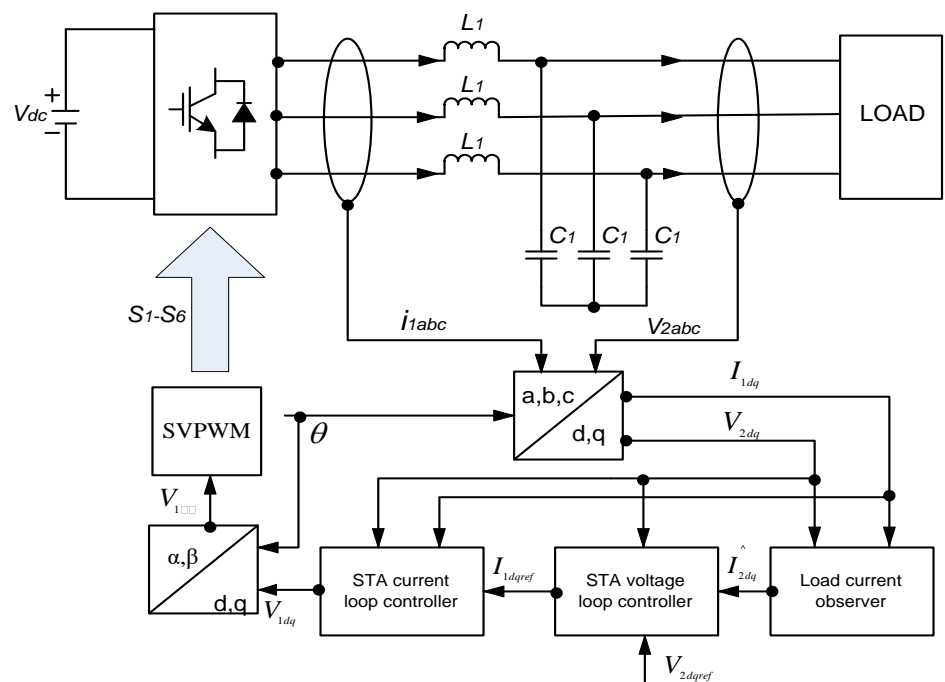

Figure 3. Schematic diagram of the STSMC and observer

\subsection{Controller design}

From in (3), the equation of inner loop current controller can be described as:

$$
\frac{d x_{1}}{d t}=-\frac{1}{L_{1}} x_{3}+w x_{2}+\frac{1}{L_{1}} V_{1 d} ; \frac{d x_{2}}{d t}=-\frac{1}{L_{1}} x_{4}-w x_{1}+\frac{1}{L_{1}} V_{1 q}
$$

The sliding variables can be chosen as:

$$
s_{1}=x_{1 \text { ref }}-x_{1}+c_{1} \int\left(x_{1 r e f}-x_{1}\right) d t ; s_{2}=x_{2 r e f}-x_{2}+c_{2} \int\left(x_{2 r e f}-x_{2}\right) d t
$$

Where $x_{1 \text { ref }} ; x_{2 \text { ref }}$ are the output current reference values. This reference values are defined as $x_{1 \text { ref }}=$ $u_{3}, x_{2 \text { ref }}=u_{4}$. Taking the time derivative of the sliding variables of the in (5) then incorporated with the in (4) leads to:

$$
\begin{aligned}
& \dot{s}_{1}=\dot{x}_{1 r e f}+c_{1}\left(x_{1 r e f}-x_{1}\right)+\frac{1}{L_{1}} x_{3}-w x_{2}-u_{1} ; \dot{s}_{2} \\
& =\dot{x}_{2 r e f}+c_{2}\left(x_{2 r e f}-x_{2}\right)-\frac{1}{L_{1}} x_{4}+w x_{1}-u_{2}
\end{aligned}
$$

Where $u_{1}=\frac{1}{L_{1}} V_{1 d} ; \quad u_{2}=\frac{1}{L_{1}} V_{1 q}$

It reveals that the system in (6) is applied one-order sliding mode control (I-SMC) strategy or twoorder sliding mode control (II-SMC) strategy. As mentioned above, the I-SMC controller causes the variable frequency of the DC/AC inverter switch, therefore increasing the chattering phenomenon. To handle this issue, the 2-STSMC controller known as STSMC is adopted. Consequently, the action control variables consist of two terms [28].

$$
u_{i}=u_{e q i}+\tilde{u}_{i}
$$

Where $\tilde{u}_{i}(i=1,2)$ denote the control variables terms which is designed by using the STSMC technical, $u_{\text {eqi }}$ denote the equivalent control terms for the nominal and unperturbed model derived by letting $\dot{s}_{i}=0, \tilde{u}_{i}=0$. As a result, the equivalent control terms $u_{e q i}$ are written as,

$$
\begin{aligned}
u_{e q 1} & =\dot{x}_{1 \text { ref }}+c_{1}\left(x_{1 r e f}-x_{1}\right)+\frac{1}{L_{1}} x_{3}-w x_{2} ; u_{e q 2} \\
& =\dot{x}_{2 r e f}+c_{2}\left(x_{2 r e f}-x_{2}\right)-\frac{1}{L_{1}} x_{4}+w x_{1}
\end{aligned}
$$

substitution of (7) and (8) into (6) produces: 


$$
\dot{s}_{i}=-\tilde{u}_{i}
$$

The equation of the control terms $\tilde{u}_{i}$ are derived from [28].

$$
\tilde{u}_{i}=k_{1 i}\left|s_{i}\right|^{1 / 2} \operatorname{sgn}\left(s_{i}\right)+\int_{0}^{t} k_{2 i} \operatorname{sgn}\left(s_{i}\right) d t
$$

Where the values $k_{1 i}$ and $k_{2 i}$ being positive gains to tuned. Next, from in (3), the equation of proposed outer loop voltage controller can be expressed as,

$$
\frac{d x_{3}}{d t}=w x_{4}+\frac{1}{C_{1}} x_{1}-\frac{1}{C_{1}} \hat{I}_{2 d} ; \frac{d x_{4}}{d t}=-w x_{3}+\frac{1}{C_{1}} x_{2}-\frac{1}{C_{1}} \hat{I}_{2 q}
$$

the sliding variables of outer loop voltage controller are selected as in (12):

$$
s_{3}=x_{3 r e f}-x_{3}+c_{3} \int\left(x_{3 r e f}-x_{3}\right) d t ; s_{4}=x_{4 r e f}-x_{4}+c_{4} \int\left(x_{4 r e f}-x_{4}\right) d t
$$

where $x_{3 r e f}, x_{4 r e f}$ are the load voltage reference values. Taking the time derivative of the sliding variable of the in (12) then incorporated with the in (11) lead to:

$$
\begin{aligned}
& \dot{S}_{3}=\dot{x}_{3 r e f}+c_{3}\left(x_{3 r e f}-x_{3}\right)-w x_{4}+\frac{1}{c_{1}} \widehat{L}_{2 d}-u_{3} ; \dot{s}_{4} \\
& =\dot{x}_{4 r e f}+c_{4}\left(x_{4 r e f}-x_{4}\right)+w x_{3}+\frac{1}{c_{1}} \widehat{L}_{2 q}-u_{4}
\end{aligned}
$$

where $\frac{1}{c_{1}} x_{1}=u_{3}, \frac{1}{C_{1}} x_{2}=u_{4}$.

The action control variables of voltage controller consists of two terms in (7) where $u_{e q i}(\mathrm{i}=3,4)$ can be determined as:

$$
\begin{aligned}
& u_{e q 3}=\dot{x}_{3 r e f}+c_{3}\left(x_{3 r e f}-x_{3}\right)-w x_{4}+\frac{1}{c_{1}} \widehat{L}_{2 d} ; u_{e q 4} \\
& =\dot{x}_{4 r e f}+c_{4}\left(x_{4 r e f}-x_{4}\right)+w x_{3}+\frac{1}{c_{1}} \hat{L}_{2 q}
\end{aligned}
$$

The STSMC terms $\tilde{u}_{3}, \tilde{u}_{4}$ are similar to the control terms which described in (10).

The block diagram of the STSMC current and voltage controller is shown in Figure 4. This block diagram is composed of the equation blocks. The inputs of the block are the state variables, observer variables, and given constant parameters, while the outputs of the block diagram are the control signals $u_{i}$.

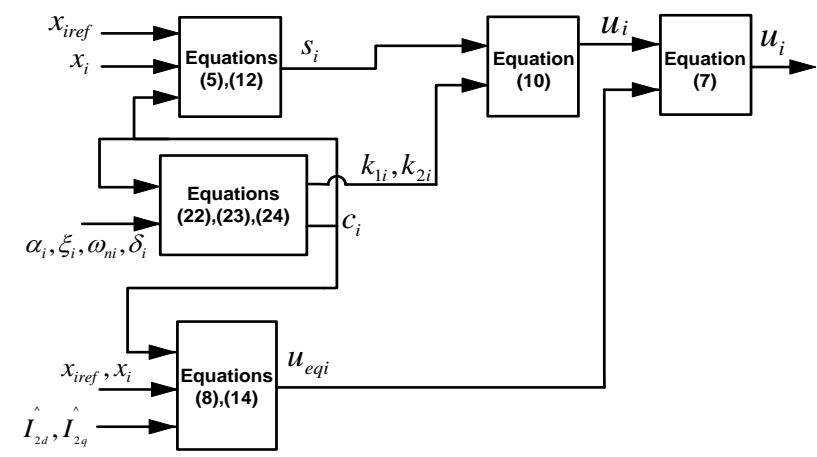

Figure 4. Block diagram of proposed STSMC current and voltage controller

\subsection{Tuning the parameters of STSMC}

The parameters tuned are $c_{i}, k_{1 i}$, and $k_{2 i}(\mathrm{i}=1: 4)$. Substitution the control law (10) to (9) lead to,

$$
\dot{s}_{i}=-k_{1 i}\left|s_{i}\right|^{1 / 2} \operatorname{sgn}\left(s_{i}\right)-\int_{0}^{t} k_{2 i} \operatorname{sgn}\left(s_{i}\right) d t
$$


it is obvious that $\operatorname{sgn}\left(s_{i}\right)=\frac{s_{i}}{\left|s_{i}\right|}$, taking the time derivative of (15) produces,

$$
\ddot{s}_{i}=-k_{1 i} \frac{\dot{s}_{i}}{2 \sqrt{\left|s_{i}\right|}}-k_{2 i} \frac{s_{i}}{\left|s_{i}\right|}
$$

from (5) and (12), the sliding variables are generalized as,

$$
s_{i}=x_{\text {iref }}-x_{i}+c_{i} \int\left(x_{\text {iref }}-x_{i}\right) d t=e_{i}+c_{i} \int e_{i} d t
$$

because of the effect of the STSMC, the sliding regime would happen and the sliding variable $s_{i}$ close to zero, so $\left|s_{i}\right| \leq \delta_{i}$ with $\delta_{i}$ are the positive constants which close to zero. Considering the most disadvantageous case, in which $\left|s_{i}\right|=\delta_{i}$, and substitution in (17) to (16) produces.

$$
\ddot{e}_{i}+\underbrace{\left(c_{i}+\frac{k_{1 i}}{2 \sqrt{\delta_{i}}}\right)}_{a_{2 i}} \dot{e}_{i}+(\underbrace{\frac{k_{1 i} c_{i}}{2 \sqrt{\delta_{i}}}+\frac{k_{2 i}}{\delta_{i}}}_{a_{1 i}}) e_{i}+\underbrace{\frac{c_{i} k_{2 i}}{\delta_{i}}}_{a_{0 i}} \int e_{i} d t=0
$$

Taking the time derivative of (18), the reflecting the $e_{i}$ error dynamics is obtained,

$$
s^{3}+a_{2 i} s^{2}+a_{1 i} s+a_{0 i} s=0
$$

where $s$ is the Laplace operator, the design of the STSMC parameters $c_{i}, k_{1 i}, k_{2 i}$ is made to ensure the poles of the characteristic in (20) equal the poles of the desired characteristic determined as,

$$
\begin{aligned}
& \left(s^{2}+2 \xi_{i} \omega_{n i} s+\omega_{n i}^{2}\right)\left(s+\alpha_{i} \xi_{i} \omega_{n i}\right) \\
& =s^{3}+\underbrace{\left(2+\alpha_{i}\right) \xi_{i} \omega_{n i}}_{b_{2 i}} s^{2}+\underbrace{\left(1+2 \alpha_{i} \xi_{i}^{2}\right) \omega_{n i}^{2}}_{b_{1 i}} s+\underbrace{\alpha_{i} \xi_{i} \omega_{n i}^{3}}_{b_{0 i}}
\end{aligned}
$$

where $s$ is the Laplace operator, the design of the STSMC parameters $c_{i}, k_{1 i}, k_{2 i}$ is made to ensure the poles of the characteristic in (20) equal the poles of the desired characteristic equation determined as,

$$
\left(s^{2}+2 \xi_{i} \omega_{n i} s+\omega_{n i}^{2}\right)\left(s+\alpha_{i} \xi_{i} \omega_{n i}\right)=s^{3}+\underbrace{\left(2+\alpha_{i}\right) \xi_{i} \omega_{n i}}_{b_{2 i}} s^{2}+\underbrace{\left(1+2 \alpha_{i} \xi_{i}^{2}\right) \omega_{n i}^{2}}_{b_{1 i}} s+\underbrace{\alpha_{i} \xi_{i} \omega_{n i}^{3}}_{b_{0 i}}(21)
$$

where the pole of desired in (21) $s_{1 i}=-\alpha_{i} \xi_{i} \omega_{n i}$ is the dominant poles, so the choice of $\alpha_{i}$ is enough high, $\xi_{i}$ is the damping coefficient, $\omega_{n i}$ is the natural frequency. The performance of the error dynamics in (19) is achieved by turning the controller parameters $c_{i}, k_{1 i}, k_{2 i}$ to guarantee $a_{2 i}=b_{2 i}, a_{1 i}=b_{1 i}, a_{0 i}=b_{0 i}$ simultaneous fulfillment. From simultaneous implementation $a_{2 i}=b_{2 i}, a_{1 i}=b_{1 i}, a_{0 i}=b_{0 i}$ the controller parameters $c_{i}, k_{1 i}, k_{2 i}$ are calculated as,

$$
\begin{aligned}
c_{i}^{3} & -\underbrace{\left(2+\alpha_{i}\right) \xi_{i} \omega_{n i}}_{b_{2 i}} c_{i}^{2}+\underbrace{\left(1+2 \alpha_{i} \xi_{i}^{2}\right) \omega_{n i}^{2}}_{b_{1 i}} c_{i}-\underbrace{\alpha_{i} \xi_{i} \omega_{n i}^{3}}_{b_{0 i}} \\
& =\left(c_{i}^{2}-2 \xi_{i} \omega_{n i} c_{i}+\omega_{n i}^{2}\right)\left(c_{i}-\alpha_{i} \xi_{i} \omega_{n i}\right)=0 \\
k_{1 i} & =2 \sqrt{\delta_{i}}\left(\left(2+\alpha_{i}\right) \xi_{i} \omega_{n i}-c_{i}\right) \\
k_{2 i} & =\frac{\alpha_{i} \xi_{i} \omega_{n i}^{3} \delta_{i}}{c_{i}}
\end{aligned}
$$

\subsection{Load current observer}

It is obvious that the STSMC requires the load current information. The information can be obtained by using sensors, but the sensors make the system more expensive and less reliable. Liu et al. [29], the authors applied the full-order observer, which causes a high computational burden in the controller. Hence, the reduce-order observer is utilized as a better option to estimate the current load. The reduced-order observer of load current is represented as,

$$
\left\{\begin{array}{l}
\dot{x}=A_{1} x+A_{2} y+B_{1} u \\
\dot{y}=A_{3} x+A_{4} y+B_{2} u
\end{array}\right.
$$


where $x=\left[\begin{array}{ll}I_{2 d} & I_{2 q}\end{array}\right]^{T}, y=\left[\begin{array}{ll}V_{2 d} & V_{2 q}\end{array}\right]^{T}, u=\left[\begin{array}{ll}I_{1 d} & I_{1 q}\end{array}\right]^{T}, A_{1}=0^{2 \times 2}, A_{2}=0^{2 x 2}$.

$$
A_{3}=\left[\begin{array}{cc}
-\frac{1}{C_{1}} & 0 \\
0 & -\frac{1}{C_{1}}
\end{array}\right] A_{4}=\left[\begin{array}{cc}
-\frac{1}{C_{1}} & 0 \\
0 & -\frac{1}{C_{1}}
\end{array}\right] B_{1}=0^{2 \times 2} B_{2}=\left[\begin{array}{cc}
\frac{1}{C_{1}} & 0 \\
0 & \frac{1}{C_{1}}
\end{array}\right]
$$

The design of a reduced-order observer rests on coordinate transformation [30]-[32].

$$
x^{\prime}=x+M_{1} y
$$

The coordinate transformation is obviously nonsingular for any $M_{1}$. The equation with respect to $x^{\prime}$ is obtained from in (25), (26).

$$
x^{\prime}=\left(A_{1}+M_{1} A_{3}\right) x^{\prime}+A_{2}^{\prime} y+\left(B_{1}+M_{1} B_{2}\right) u
$$

Where $A_{2}^{\prime}=A_{2}+M_{1} A_{4}-\left(A_{1}+M_{1} A_{3}\right) M_{1}$. An observer is designed by,

$$
\hat{x^{\prime}}=\left(A_{1}+M_{1} A_{3}\right) \hat{x^{\prime}}+A_{2}^{\prime} y+\left(B_{1}+M_{1} B_{2}\right) u
$$

with $x^{\prime}$ is an estimate of the state vector $x^{\prime}$.

In this section, $M_{1}$ is simply chosen $\operatorname{as} M_{1}=\left[\begin{array}{cc}m_{1} & 0 \\ 0 & m_{2}\end{array}\right]$ and incorporated with (28), the reducedorder observer of load current can be rewritten as,

$$
\hat{x_{1}^{\prime}}=-\frac{m_{1}}{C_{1}} \hat{x_{1}^{\prime}}+\frac{m_{1}^{2}}{C_{1}} V_{2 d}+\frac{m_{1}}{C_{1}} V_{2 q}+\frac{m_{1}}{C_{1}} I_{1 d} ; \hat{x_{2}^{\prime}}=-\frac{m_{2}}{C_{1}} \hat{x_{2}^{\prime}}+\frac{m_{2}^{2}}{C_{1}} V_{2 q}-\frac{m_{2}}{C_{1}} V_{2 d}+\frac{m_{2}}{C_{1}} I_{1 q}
$$

where $x^{\prime}=\left[\begin{array}{ll}x_{1}^{\prime} & x_{2}^{\prime}\end{array}\right]^{T}$, from (26), the load current observer is obtained as:

$$
\hat{x_{1}}=\hat{x_{1}^{\prime}}-m_{1} V_{2 d} ; \hat{x_{2}}=\hat{x_{2}^{\prime}}-m_{2} V_{2 q}
$$

The block diagram of the load current observer is expressed in Figure 5.

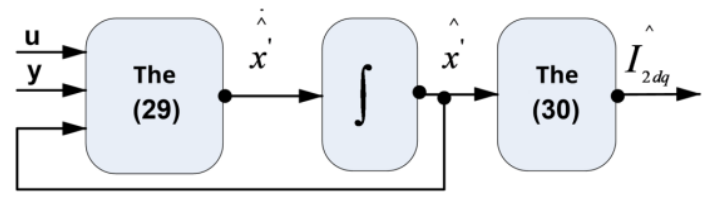

Figure 5. Block diagram of load current observer

\section{RESULTS AND DISCUSSION}

In this section, we utilized the MATLAB/Simulink to evaluate the efficiency of proposed observer and controller. The simulation model of the DGS is defined by the stiff DC voltage source, DC-AC inverter with an LC filter connected to the various loads, the STSMC, and the reduce-order observer. The nominal parameters employed in these simulations are listed in Table 1. During the simulation process, the discrete model is designed with a time step of $2 \mu \mathrm{s}$. The switching frequency converters are set at $5 \mathrm{kHz}$. The parameters of STSMC for the current loop control and the voltage loop control can be turned as:

$$
\begin{aligned}
& \alpha_{1}=500, \xi_{1}=1, \omega_{n 1}=100, \delta_{1}=0.05, c_{1}=100 ; \alpha_{2}=500, \xi_{2}=1, \omega_{n 2}=100, \delta_{2}=0.05, c_{2}= \\
& \begin{array}{l}
100 \\
0.05, c_{4}=100
\end{array}
\end{aligned}
$$

The variables of the matrix $M_{1}$ can be chosen as follows: $m_{1}=0.005, m_{2}=0.01$. 
We conducted the simulations under the following different cases to illustrate the excellent performance of the proposed observer and STSMC controller:

- Case 1) Resistive pulse load ( $\mathrm{R}=80 \Omega$; $\mathrm{L}=0.1 \mathrm{H}$; Sudden load change $100 \%$ to $0 \%$ and $0 \%$ to $100 \%$ ).

- Case 2) Resistive and inductive pulse load ( $\mathrm{R}=80 \Omega ; \mathrm{L}=0.1 \mathrm{H}$; Sudden load change $100 \%$ to $0 \%$ and $0 \%$ to $100 \%)$.

- Case 3) Unbalanced resistive load ( $\mathrm{R}=80 \Omega$; Closed phase A)

- Case 4) Nonlinear load ( $R=200 \Omega, C=680 \mu \mathrm{F}, \mathrm{L}=10 \mathrm{mH}$; A three-phase diode rectifier)

Table 1. DGS properties

\begin{tabular}{lc}
\hline \multicolumn{1}{c}{ Parameters } & Value \\
\hline DGS rated power & $450 \mathrm{VA}$ \\
dc-link voltage & $280 \mathrm{Vdc}$ \\
Switching frequency & $5 \mathrm{KHz}$ \\
Nominal load output voltages & $110 \mathrm{~V}$ \\
Fundamental frequency & $60 \mathrm{~Hz}$ \\
Filter capacitance & $6.67 \mu \mathrm{F}$ \\
Filter Inductance & $10 \mathrm{mH}$ \\
\hline
\end{tabular}

Figures 6 (a)-(b) and Figures 7 (a)-(b) demonstrate the simulation results of the proposed controller among different cases. Figure 6 shows the transient trends of the load voltage, the inverter current, and the load current under case 1 and case 2 . The transient time is very short, at about $0.02 \mathrm{~s}$. It can be seen that the load voltages are only slightly distorted during the transient time. Furthermore, the load voltages still maintain a good performance in case of the unbalance loads (Figure 7-case 3). In case 4, it is critical to note that the waveforms of the load voltages keep the sinusoidal form with a slight distortion while the waveforms of the inverter current and the load current are relatively distorted. In addition, the estimations of the load current are also presented. As highlighted in Figure 7, the proposed observer estimates and validates the load current precisely. The oscillation amplitude of the load current estimations is smaller compared to the figures of the measured load current. It demonstrates the excellent performance of the proposed reduced-order observer of the load current under different conditions.

Figures 8 (a)-(d) shows the simulation results of a standard sliding mode controller under the aforementioned cases. The performances of the load voltage, the inverter current, and load current are showed to compare with the STSMC. Furthermore, the steady-state and the THD performance of the load voltages using the proposed controller and the traditional sliding controller are shown in Tables 2 and 3 respectively.
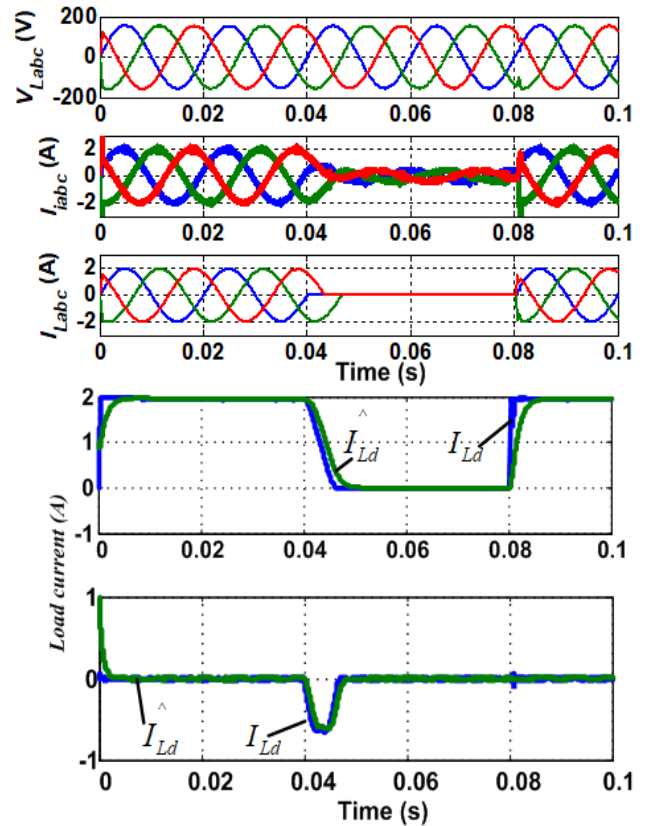

(a)
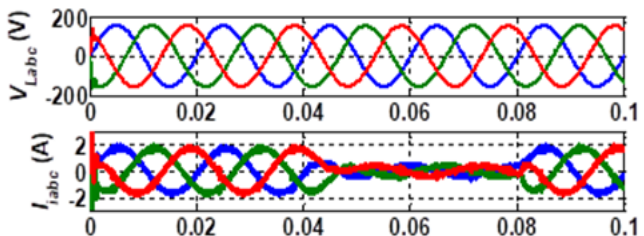

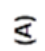
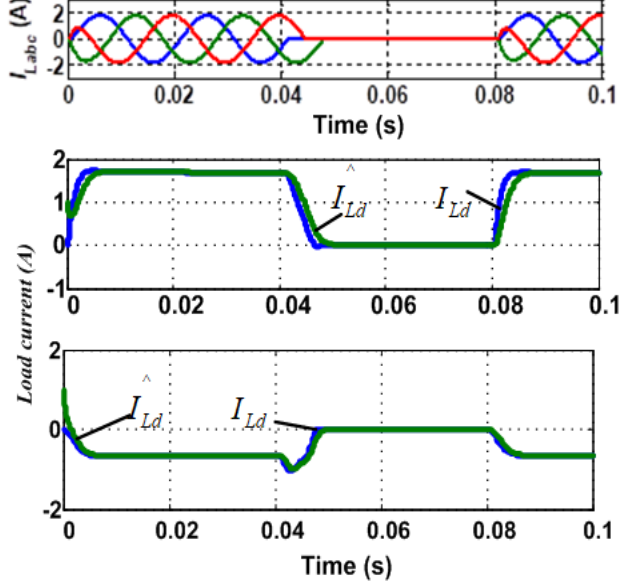

(b)

Figure 6. Simulation results of STSMC under (a) case 1 and (b) case 2 

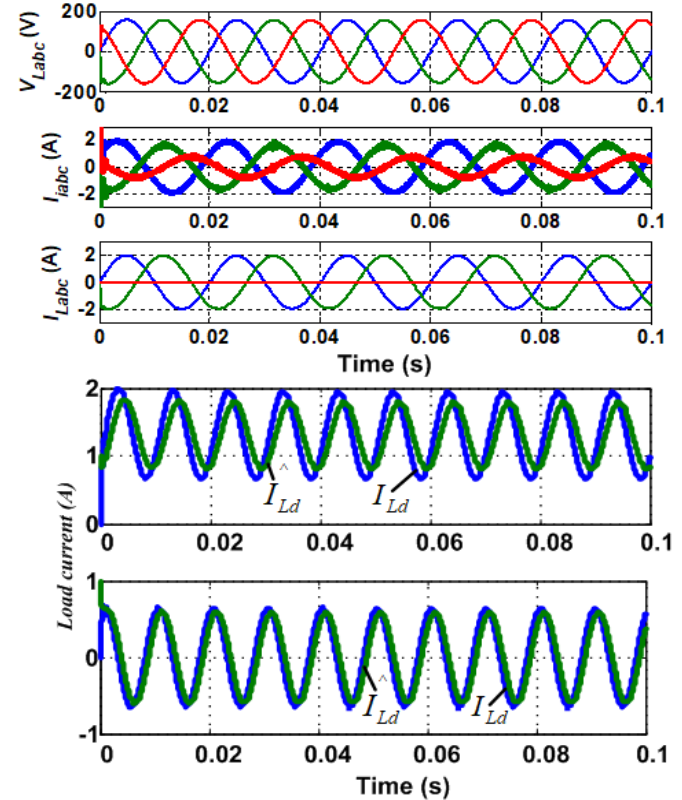

(a)
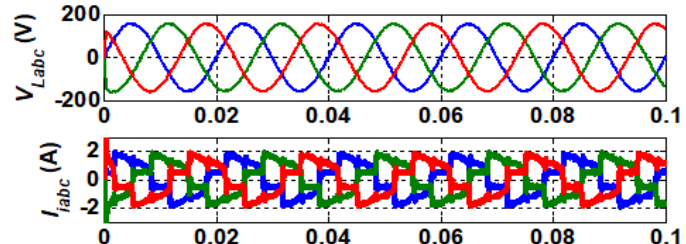

\2
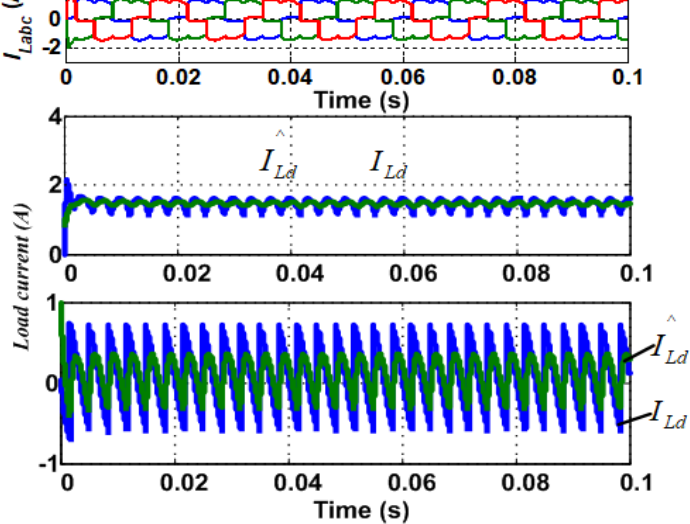

(b)

Figure 7. Simulation results of STSMC under (a) case 3 and (b) case 4
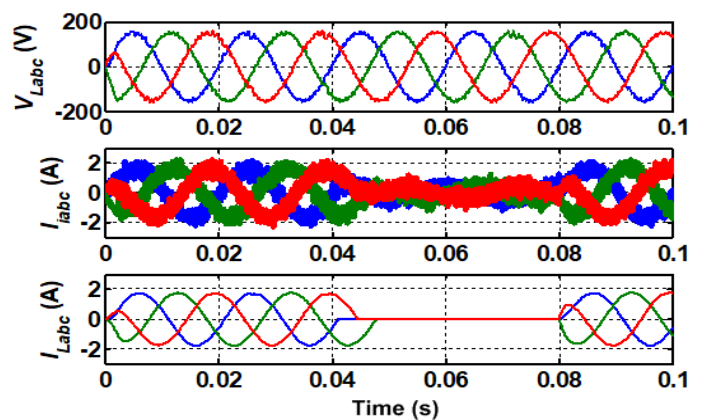

(a)
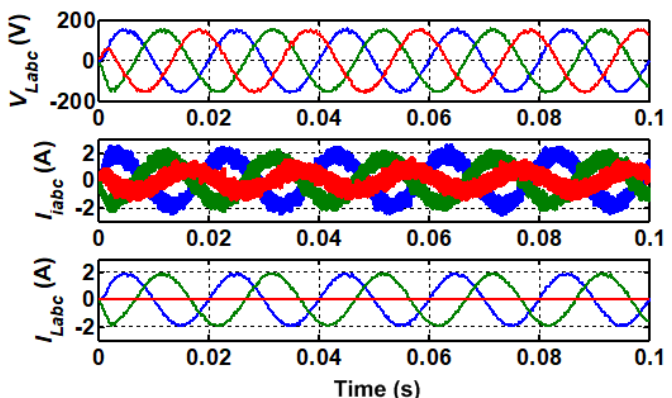

(c)
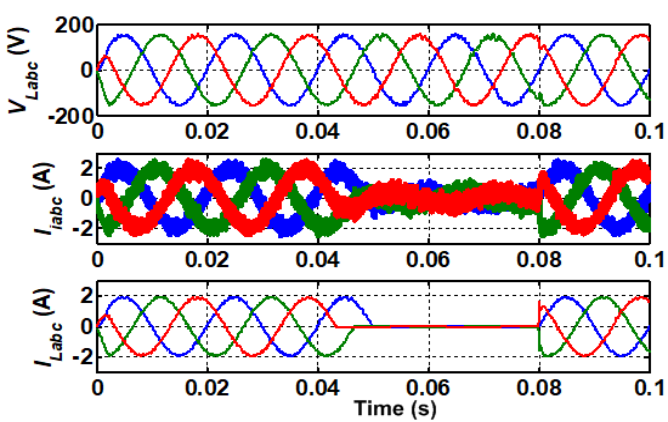

(b)
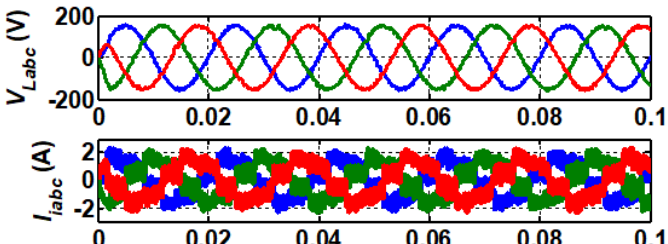

¿ 2

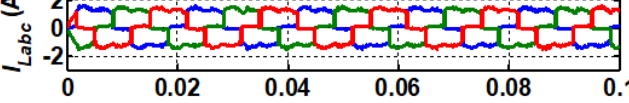

(d)

Figure 8. Simulation results of the standard sliding controller under (a) case 1, (b) case 2, (c) case 3, and (d) case 4

Table 3 compares the THD results between the proposed method and the other controllers among different types of loads. Generally, it is clear that the THD rate of the proposed method in the case of the balanced resistive load is the lowest, at about $0.05 \%$. By contrast, the figures for the standard sliding controller and the adaptive voltage controller are much higher, nearly $2.15 \%$ and $0.094 \%$ respectively. In addition, for the nonlinear load, the THD proportion of the proposed control is noticeably low, at about 
$0.402 \%$ in average. On the other hand, the percentages of the standard sliding controller and the adaptive voltage controller always maintain over $0.405 \%$. Furthermore, the results illustrates that the proposed system could work effectively even in case of the unbalanced resistive load or the nonlinear load with the THD rates down to $0.075 \%$.

Table 2. Steady-state performance of the load voltages

\begin{tabular}{lccccccccc}
\hline \multirow{2}{*}{ Load types } & \multicolumn{2}{c}{ The proposed control } & \multicolumn{2}{c}{ The standard sliding controller } & \multicolumn{2}{c}{ The adaptive voltage controller } \\
& \multicolumn{2}{c}{ Load voltages $(\mathrm{V})$} & \multicolumn{3}{c}{ Load voltages (V) } & \multicolumn{3}{c}{ Load voltages (V) } \\
& $V_{L a}$ & $V_{L b}$ & $V_{L c}$ & $V_{L a}$ & $V_{L b}$ & $V_{L c}$ & $V_{L a}$ & $V_{L b}$ & $V_{L c}$ \\
\hline Balanced resistive load & 110.01 & 110.03 & 109.95 & 109.4 & 109.2 & 108.9 & 109.72 & 109.72 & 109.72 \\
Unbalanced resistive load & 110.12 & 110.1 & 109.9 & 108.6 & 108.85 & 108.8 & 109.9 & 109.75 & 109.52 \\
Nonlinear load & 110.35 & 110.32 & 110.28 & 109.5 & 109.3 & 109.1 & 109.52 & 109.51 & 109.52 \\
\hline
\end{tabular}

Table 3. The total harmonic distortion of the load voltages

\begin{tabular}{lccc}
\hline \multicolumn{1}{c}{ Load types } & $\begin{array}{c}\text { The proposed control } \\
\text { THD }(\%)\end{array}$ & $\begin{array}{c}\text { The standard sliding controller } \\
\text { THD }(\%)\end{array}$ & $\begin{array}{c}\text { The adaptive voltage controller } \\
\text { THD }(\%)\end{array}$ \\
\hline Balanced resistive load & 0.05 & 2.15 & 0.094 \\
Unbalanced resistive load & 0.075 & 2.33 & 0.08 \\
Nonlinear load & 0.402 & 2.06 & 0.405 \\
\hline
\end{tabular}

\section{CONCLUSION}

In this paper, the STSMC of a three-phase inverter is designed to ensure the good performance of the load voltage among various load conditions. The proposed STSMC is developed for the outer-loop voltage controller and inner-loop current controller. Hence, it is not only easy to implement but also requires little computational effort. Furthermore, we have found an innovative reduced-order observer to estimate the load currents precisely. Hence, the parameter calculations are more robust to system disturbances. However, one minor limitation of our research is the harmonic distortion of the inverter current in the case of the nonlinear loads. As is well known, the high THD of the inverter current is extremely hard to control and could not be eliminated completely. We propose that further research should be undertaken in this mentioned area. In general, the paper points out the advantages of the proposed controller and observer based on the MATLAB/Simulink. The simulation results have indicated the feasibility and effectiveness of the proposed approach.

\section{REFERENCES}

[1] W. Li, Y. Liu, H. Liang, and Y. Shen, "A New Distributed Energy Management Strategy for Smart Grid with Stochastic Wind Power," IEEE Transactions on Industrial Electronics, vol. 68, no. 2, pp. 1311-1321, 2021, doi: 10.1109/TIE.2020.2970627.

[2] A. Sinha and K. C. Jana, "Comprehensive review on control strategies of parallel-interfaced voltage source inverters for distributed power generation system," IET Renewable Power Generation, vol. 14, no. 13, pp. 2297-2314, 2020, doi: 10.1049/ietrpg.2019.1067.

[3] J. Lai, X. Lu, and X. Yu, "Stochastic Distributed Frequency and Load Sharing Control for Microgrids with Communication Delays,” IEEE Systems Journal, vol. 13, no. 4, pp. 4269-4280, 2019, doi: 10.1109/JSYST.2019.2901711.

[4] Y. Huang, Y. Jiang, and J. Wang, “Adaptability Evaluation of Distributed Power Sources Connected to Distribution Network," IEEE Access, vol. 9, pp. 42409-42423, 2021, doi: 10.1109/ACCESS.2021.3066206.

[5] B. Rajapandian and G. T. Sundarrajan, "Evaluation of DC-DC converter using renewable energy sources," International Journal of Power Electronics and Drive Systems, vol. 11, no. 4, pp. 1918-1925, 2020, doi: 10.11591/ijpeds.v11.i4.pp1918-1925.

[6] M. Regad, M. H. Helaimi, R. Taleb, A. M. Othman, and H. A. Gabbar, "Control of hybrid power system based renewable energy generations using PID controller,” International Journal of Power Electronics and Drive Systems, vol. 11, no. 4, pp. 1775-1784, 2020, doi: 10.11591/ijpeds.v11.i4.pp1775-1784.

[7] K. K. M. Siu and C. N. M. Ho, "Generalized design approach of a family of grid-connected converters based on active virtual ground technique for single-phase AC microgrid applications," CPSS Transactions on Power Electronics and Applications, vol. 5, no. 3, pp. 203-212, 2020, doi: 10.24295/CPSSTPEA.2020.00017.

[8] E. E. Pompodakis, G. C. Kryonidis, C. Demoulias, and M. C. Alexiadis, "A Generic Power Flow Algorithm for Unbalanced Islanded Hybrid AC/DC Microgrids," IEEE Transactions on Power Systems, vol. 36, no. 2, pp. 1107-1120, March 2021, doi: 10.1109/TPWRS.2020.3012815.

[9] J. Chen, D. Yue, C. Dou, L. Chen, S. Weng, and Y. Li, “A Virtual Complex Impedance Based \$P-Idot\{V\}\$ Droop Method for Parallel-Connected Inverters in Low-Voltage AC Microgrids," IEEE Transactions on Industrial Informatics, vol. 17, no. 3, pp. 1763-1773, 2021, doi: 10.1109/TII.2020.2997054.

[10] M. Merai, M. W. Naouar, I. Slama-Belkhodja, and E. Monmasson, "An Adaptive PI Controller Design for DC-Link Voltage Control of Single-Phase Grid-Connected Converters," IEEE Transactions on Industrial Electronics, vol. 66, no. 8, pp. 6241-6249, 2019, doi: 10.1109/TIE.2018.2871796.

[11] H. Zhang, H. Li, Y. Zhou, and S. Zeng, "Cascaded Proportional Control with Algebraic Estimators for PFC AC/DC Converters," IEEE Transactions on Power Electronics, vol. 34, no. 12, pp. 12504-12512, 2019, doi: 10.1109/TPEL.2019.2907652. 
[12] A. H. Yazdavar, M. F. Shaaban, E. F. El-Saadany, M. M. A. Salama, and H. H. Zeineldin, "Optimal Planning of Distributed Generators and Shunt Capacitors in Isolated Microgrids with Nonlinear Loads," IEEE Transactions on Sustainable Energy, vol. 11, no. 4, pp. 2732-2744, 2020, doi: 10.1109/TSTE.2020.2973086.

[13] J. He, C. Chok You, X. Zhang, Z. Li, and Z. Liu, “An Adaptive Dual-Loop Lyapunov-Based Control Scheme for a Single-Phase UPS Inverter," IEEE Transactions on Power Electronics, vol. 35, no. 9, pp. 8886-8891, 2020, doi: 10.1109/TPEL.2020.2974548.

[14] L. Zheng, F. Jiang, J. Song, Y. Gao and M. Tian, "A Discrete-Time Repetitive Sliding Mode Control for Voltage Source Inverters," IEEE Journal of Emerging and Selected Topics in Power Electronics, vol. 6, no. 3, pp. 1553-1566, 2018, doi: 10.1109/JESTPE.2017.2781701.

[15] N. Marati and D. Prasad, "A Modified Feedback Scheme Suitable for Repetitive Control of Inverter with Nonlinear Load," IEEE Transactions on Power Electronics, vol. 33, no. 3, pp. 2588-2600, 2018, doi: 10.1109/TPEL.2017.2690361.

[16] N. Lu, S. Yang, and Y. Tang, "Ripple Current Reduction for Fuel-Cell-Powered Single-Phase Uninterruptible Power Supplies," IEEE Transactions on Industrial Electronics, vol. 64, no. 8, pp. 6607-6617, 2017, doi: 10.1109/TIE.2017.2677329.

[17] A. E. Lucena da Costa, C. B. Jacobina, N. Rocha, and P. L. S. Rodrigues, "Single-Phase AC-DC-AC Five-Leg Multilevel Converter," IEEE Transactions on Industry Applications, vol. 57, no. 2, pp. 1535-1544, 2021, doi: 10.1109/TIA.2020.3045959.

[18] S. -K. Kim and C. K. Ahn, "Proportional-Derivative Voltage Control with Active Damping for DC/DC Boost Converters via Current Sensorless Approach," IEEE Transactions on Circuits and Systems II: Express Briefs, vol. 68, no. 2, pp. 737-741, 2021, doi: 10.1109/TCSII.2020.3008432.

[19] H. Komurcugil, "Rotating-Sliding-Line-Based Sliding-Mode Control for Single-Phase UPS Inverters," IEEE Transactions on Industrial Electronics, vol. 59, no. 10, pp. 3719-3726, 2012, doi: 10.1109/TIE.2011.2159354.

[20] D. Sun, X. Wang, H. Nian, and Z. Q. Zhu, "A Sliding-Mode Direct Power Control Strategy for DFIG Under Both Balanced and Unbalanced Grid Conditions Using Extended Active Power," IEEE Transactions on Power Electronics, vol. 33, no. 2, pp. 13131322, 2018, doi: 10.1109/TPEL.2017.2686980.

[21] M. Pichan and H. Rastegar, "Sliding-Mode Control of Four-Leg Inverter with Fixed Switching Frequency for Uninterruptible Power Supply Applications," IEEE Transactions on Industrial Electronics, vol. 64, no. 8, pp. 6805-6814, 2017, doi: 10.1109/TIE.2017.2686346.

[22] P. Ge et al., "Extended-State-Observer-Based Distributed Robust Secondary Voltage and Frequency Control for an Autonomous Microgrid," IEEE Transactions on Sustainable Energy, vol. 11, no. 1, pp. 195-205, 2020, doi: 10.1109/TSTE.2018.2888562.

[23] V. Nguyen, C. Lin, S. Su, N. Nguyen and Q. Tran, "Adaptive PD networks tracking control with full-state constraints for redundant parallel manipulators," Joint 17th World Congress of International Fuzzy Systems Association and 9th International Conference on Soft Computing and Intelligent Systems (IFSA-SCIS), 2017, pp. 1-5, doi: 10.1109/IFSA-SCIS.2017.8023289.

[24] Y. Belkhier et al., "Intelligent Energy-Based Modified Super Twisting Algorithm and Factional Order PID Control for Performance Improvement of PMSG Dedicated to Tidal Power System," IEEE Access, vol. 9, pp. 57414-57425, 2021, doi: 10.1109/ACCESS.2021.3072332.

[25] V. Nguyen, C. Lin, S. Su, and Q. Tran, "Adaptive PID tracking control based radial basic function networks for a 2-DOF parallel manipulator," International Conference on System Science and Engineering (ICSSE), 2017, pp. 309-312, doi: 10.1109/ICSSE.2017.8030887.

[26] V. T. Nguyen, C.Y. Lin, S. F. Su, and Q.V. Tran, "Adaptive chattering free neural network based sliding mode control for trajectory tracking of redundant parallel manipulators," Asian J. Cont., vol. 21, no. 2, pp. 908-923, 2019, doi: 10.1002/asjc.1789.

[27] V. T. Nguyen, C. -Y. Lin, S. -F. Su, W. Sun and M. J. Er, "Global Finite Time Active Disturbance Rejection Control for Parallel Manipulators with Unknown Bounded Uncertainties," IEEE Transactions on Systems, Man, and Cybernetics: Systems, vol. 51, no. 12, pp. 7838-7849, 2021, doi: 10.1109/TSMC.2020.2987056.

[28] Y. Huangfu, S. Zhuo, F. Chen, S. Pang, D. Zhao, and F. Gao, "Robust Voltage Control of Floating Interleaved Boost Converter for Fuel Cell Systems," IEEE Transactions on Industry Applications, vol. 54, no. 1, pp. 665-674, 2018, doi: 10.1109/TIA.2017.2752686.

[29] F. Liu, Y. Li, Y. Cao, J. She, and M. Wu, “A Two-Layer Active Disturbance Rejection Controller Design for Load Frequency Control of Interconnected Power System," IEEE Transactions on Power Systems, vol. 31, no. 4, pp. 3320-3321, 2016, doi: 10.1109/TPWRS.2015.2480005

[30] V. Utkin, J. Guldner, and J. Shi, "Sliding Mode Control in Electro-Mechanical Systems," Taylor and Francis Group, CRC Press, pp. 1-503, 2009, doi: 10.1201/9781420065619.

[31] J. Lu, M. Savaghebi, A. M. Y. M. Ghias, X. Hou, and J. M. Guerrero, “A Reduced-Order Generalized Proportional Integral Observer-Based Resonant Super-Twisting Sliding Mode Control for Grid-Connected Power Converters," IEEE Transactions on Industrial Electronics, vol. 68, no. 7, pp. 5897-5908, 2021, doi: 10.1109/TIE.2020.2998745.

[32] V. Nguyen, S. Su, A. Nguyen, and V. Nguyen, "Adaptive Nonsingular Fast Terminal Sliding Mode Tracking Control for Parallel Manipulators with Uncertainties," International Conference on System Science and Engineering (ICSSE), 2019, pp. 522-525, doi: 10.1109/ICSSE.2019.8823137.

\section{BIOGRAPHIES OF AUTHORS}

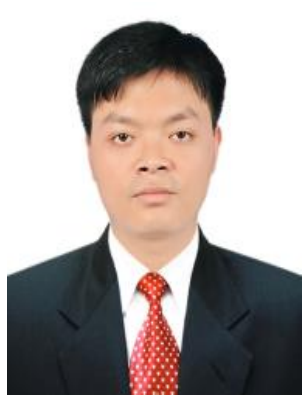

Dinh Hieu Phan (iD) SC $\mathrm{S}$ received his B.S., M.S. in Automation Engineering from Hanoi University of Science and Technology, Hanoi, Vietnam, in 2006 and 2008 and received his Ph.D. degree in Electrical Engineering from Hunan University, China in 2016. He has worked at Mechatronics Department Mechanical Faculty of Hanoi University of Industry since 2008. His current research interests include robotics control, electric machine control and control of distributed generation systems using renewable energy sources. He can be contacted at email: phandinhhieu@ haui.edu.vn. 

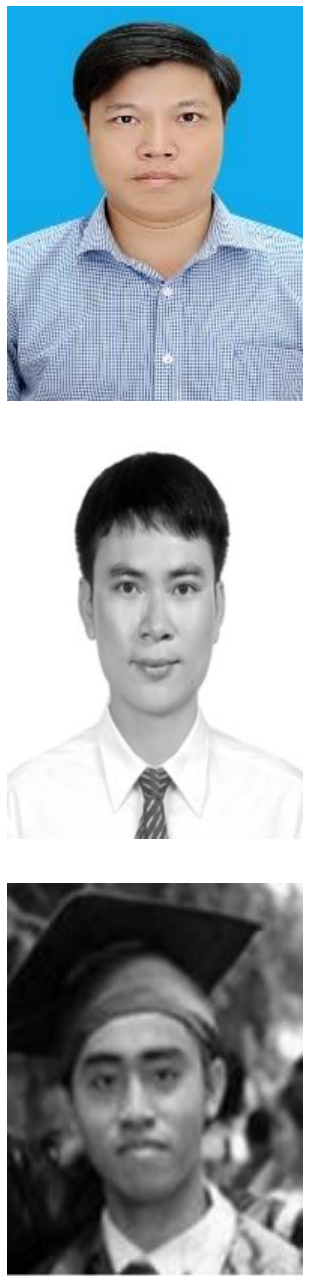

Huy Anh Bui (D) 8d SC P received the B.S. degree in electrical and electronics engineering from Ho Chi Minh City University of Technology, Ho Chi Minh, Vietnam in 2018, and the M.S. degree in electrical engineering from Hanoi University of Science and Technology, Hanoi, Vietnam, in 2020. Since 2020, he has been a lecturer with the Department of Mechatronics Engineering (ME), Hanoi University of Industry, Hanoi, Vietnam. His current research interests include robotics, AI, intelligent control systems, and computer vision applications. He can be contacted at email: buihuyanh@ haui.edu.vn.
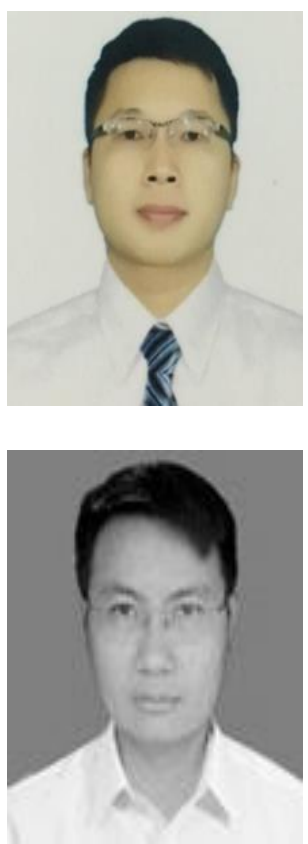

Ngoc Duy Lê (iD IS SC P received the B.S. degrees in machanical engineering and M.S. degrees in electronic engineering from VNU University of Engineering and Technology, Hanoi, Vietnam in 2009 and 2011Since 2010, he has been a Lecturer with the Department of Mechatronics Engineering, Hanoi University of Industry, Hanoi. His current research interests intelligent control systems, mobile robots, hydraulic and pneumatic systems, sensor system and signal processing. He can be contacted at email: lengocduy@haui.edu.vn.

Thanh Lam Bui (iD 8I SC P received the B.S. degree in mechatronics engineering from Phuong Dong University, Hanoi, Vietnam in 2006, the M.S. degree in mechatronics engineering from Military Technical Academy, Hanoi, Vietnam in 2012, and the Ph.D. degree in mechanical engineering from Hanoi University of Science and Technology, Hanoi, Vietnam in 2018. Since 2007, he has been a lecturer with the Department of Mechatronics Engineering (ME), Hanoi University of Industry, Hanoi, Vietnam. His current research interests include robotics, intelligent control systems, and nano technology. He can be contacted at email: thanhlam710@gmail.com. 